\title{
Cerebellar Herniation after Lumbar Puncture in Galactosemic Newborn
}

\author{
Salih Kalay, M.D., ${ }^{1}$ Osman Öztekin, M.D., ${ }^{1}$ Gönül Tezel, M.D., ${ }^{1}$ \\ Hakan Demirtaş, M.D., ${ }^{2}$ Mustafa Akçakuş, M.D.,' ${ }^{1}$ and Nihal Oygür, M.D. ${ }^{1}$
}

\begin{abstract}
Cerebral edema resulting in elevated intracranial pressure is a well-known complication of galactosemia. Lumbar puncture was performed for the diagnosis of clinically suspected bacterial meningitis. Herniation of cerebral tissue through the foramen magnum is not a common problem in neonatal intensive care units because of the open fontanelle in infants. We present the case of a 3-week-old infant with galactosemia who presented with signs of cerebellar herniation after lumbar puncture.
\end{abstract}

KEYWORDS: Newborn, galactosemia, lumbar puncture, herniation

Galactosemia is a rare autosomal-recessive metabolic disorder affecting 1 in 30,000 to 60,000 infants. Hereditary galactosemia is among the most common carbohydrate metabolism disorders and can be lifethreatening during the newborn period. During the initial hospitalization for a child with symptomatic severe classic galactosemia, the major concerns are sepsis, bleeding, liver dysfunction, and brain swelling. ${ }^{1}$ Cerebral edema with resulting elevated intracranial pressure is a well-known complication of galactosemia. We present the case of a 3-week-old infant with galactosemia who presented with signs of cerebellar herniation after lumbar puncture (LP).

\section{CASE REPORT}

A 22-day-old female infant was referred to the neonatal intensive care unit because of feeding difficulties, lethargy, jaundice, and hepatomegaly. She was born at 40 weeks' gestation by uncomplicated vaginal delivery. Her weight was $3200 \mathrm{~g}$. Prenatal and natal history was unremarkable. The Apgar scores were 8 and 9 at
1 and 5 minutes, respectively. On the second day of life, she was hospitalized because of jaundice and given phototherapy for 10 days. After discharge, she stayed at home until day 22 of postnatal life and showed progressive lethargy, feeding intolerance, and prolonged hyperbilirubinemia. Family history was unremarkable for metabolic disorders. There was no consanguinity between the parents. Her two brothers died about 3 months of age.

On initial evaluation, the patient was lethargic with a temperature of $36.8^{\circ} \mathrm{C}$, pulse of 158 beats per minute, respiratory rate of 52 breaths per minute, blood pressure of 78/36 $\mathrm{mm} \mathrm{Hg}$, and oxygen saturation of $98 \%$ on room air. Physical examination revealed bulging anterior fontanel, jaundice, hepatomegaly, and ascites. The pupils were equal in size and reactive to light. The patient was hypoactive and hypotonic. She was not dehydrated and appeared to be in a fairly satisfactory state of nutrition. The liver was enlarged to $5 \mathrm{~cm}$ below the costal margin along the midclavicular line, and there was moderate ascites. There were no petechial lesions or mucosal bleeds.
Departments of ${ }^{1}$ Neonatology and ${ }^{2}$ Radiology, Akdeniz University School of Medicine, Antalya, Turkey.

Address for correspondence and reprint requests: Salih Kalay, M.D., Department of Neonatology, Akdeniz University, School of Medicine, Antalya 07070, Turkey (e-mail: salihkalay@hotmail.com).

Am J Perinatol Rep 2011;1:43-46. Copyright (C) 2011 by Thieme
Medical Publishers, Inc., 333 Seventh Avenue, New York, NY 10001, USA. Tel: +1(212) 584-4662.

Received: January 27, 2011. Accepted after revision: March 4, 2011. Published online: April 11, 2011.

DOI: http://dx.doi.org/10.1055/s-0031-1277101.

ISSN 2157-6998. 
A
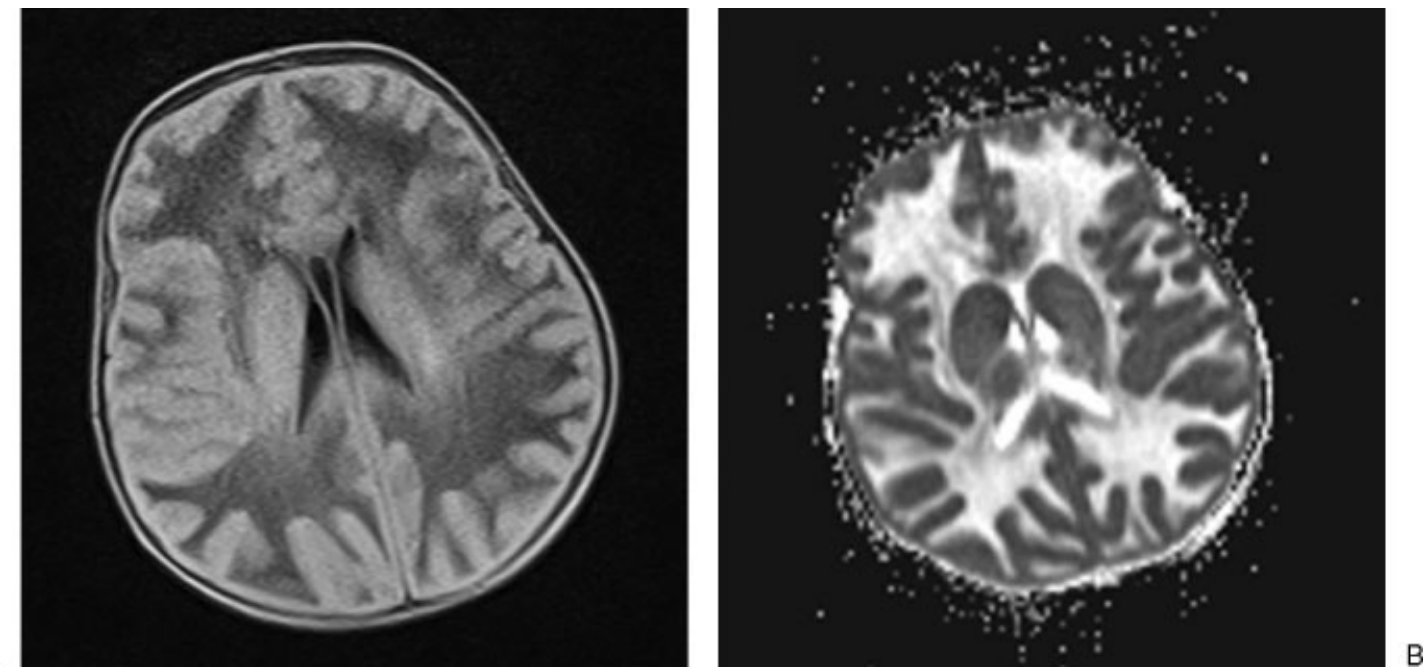

Figure 1 Diffusion-weighted magnetic resonance image (A) and apparent diffusion coefficient map (B) show extensive ischemia in the brain stem and supratentorial brain with relative sparing of the white matter.

Laboratory studies showed hemoglobin $13.4 \mathrm{~g} / \mathrm{dL}$, leukocytes $28 \times 10^{9} / \mathrm{L}$, and platelets $547 \times 10^{9} / \mathrm{L}$. Serum C-reactive protein value was $3 \mathrm{mg} / \mathrm{dL}$ (normal 0 to 1 ). The patient had normal red cell morphology with occasional polychromasia, reticulocyte count of $4.6 \%$ in blood smear, and immature to total neutrophil ratio on admission (0.22). The biochemical markers were as follows: glucose $85 \mathrm{mg} / \mathrm{dL}$, serum aspartate aminotransferase $314 \mathrm{IU} / \mathrm{L}$, alanine aminotransferase $257 \mathrm{IU} / \mathrm{L}$, alkaline phosphatase $314 \mathrm{IU} / \mathrm{L}$, gamma-glutamyltransferase 14 IU/L, total bilirubin $11.5 \mathrm{mg} / \mathrm{dL}$, conjugated bilirubin $10.6 \mathrm{mg} / \mathrm{L}$, albumin $2.2 \mathrm{~g} / \mathrm{dL}$, blood urea nitrogen 31 $\mathrm{mg} / \mathrm{dL}$, and creatinine $1.48 \mathrm{mg} / \mathrm{dL}$. Prothrombin time and activated partial thromboplastin time were 23 (10.0 to 15.0 ) and 79 seconds ( 26 to 55 seconds), respectively. Plasma ammonium was $339 \mu \mathrm{mol} / \mathrm{L}$ (reference range: 64 to $107 \mu \mathrm{mol} / \mathrm{L}$ ), and plasma lactate level was only mildly elevated $(3.7 \mathrm{mmol} / \mathrm{L})$. Arterial blood gases (room air) showed $\mathrm{pH}$ of 7.25 , base deficit of $-7.2, \mathrm{PCO}_{2} 45 \mathrm{~mm}$ $\mathrm{Hg}, \mathrm{HCO}_{3} 17 \mathrm{mmol} / \mathrm{L}, \mathrm{PO}_{2} 74 \mathrm{~mm} \mathrm{Hg}$, and $\mathrm{O}_{2}$ saturation 91\%. LP was performed for the diagnosis of clinically suspected bacterial meningitis. Cerebrospinal fluid (CSF) analysis showed a white blood cell count of $60 / \mathrm{mm}^{3}$ with $70 \%$ polymorphonuclear cells and $30 \%$ lymphocytes, glucose $55 \mathrm{mg} / \mathrm{dL}$, and protein $93.3 \mathrm{mg} /$ $\mathrm{dL}$, with negative Gram stain. Blood, urine, and CSF culture were negative. Fifteen minutes after the LP, she became hypotensive with shallow respirations and exhibited posture change. She was promptly intubated and stabilized with mechanical ventilation. The pupils were fixed and dilated with absent corneal and gag reflexes.

The clinical suspicion of galactosemia was strengthened by finding positive reducing substances in the urine. All other investigations including TORCH (Toxoplasma gondii, rubella, cytomegalovirus, and herpes simplex virus) serology and amino acids in the blood and urine level were normal.
Abdominal ultrasonography revealed an enlarged liver with ascites.

Diffusion-weighted magnetic resonance images revealed edema and diffuse cortical diffusion restriction (Fig. 1). T1- and T2-weighted images revealed intensity increase in the deep white matter of both cerebral hemispheres and edema of the entire cerebral hemisphere and basal ganglia structures. The cerebellar tonsils were "herniated" through the foramen magnum into the upper cervical spinal canal (Fig. 2).

The enzyme activity of galactose + phosphate uridyl transferase (GALT) was further determined quantitatively in erythrocyte lysate (by H.K.J.) by an isotopic method using carbon-14 galactose-1-phosphate and uridine diphosphate galactose-glucose. GALT activity in the patient was $0.55 \mathrm{U} / \mathrm{g}$ hemoglobin $(>3)$. Three common mutations of GALT gene in classical galactosemia, Q188R, S135L, and N314D, were screened by polymerase chain reaction amplification of genomic DNA and restriction digestion. Homozygous Q188R mutation was observed.

\section{DISCUSSION}

Galactosemia is a disorder caused by a deficiency of any of the three possible enzymes involved in the metabolism of galactose: galactokinase, transferase, or epimerase. The natural history of classical galactosemia is lethargy, poor feeding, jaundice, and hepatomegaly. These findings appear within days of the initiation of milk feedings. Progression of this acute neonatal toxicity syndrome may include the development of Escherichia coli septicemia in the second week of life, coagulopathy, hyperchloremic metabolic acidosis with aminoaciduria, and vitreous hemorrhage. ${ }^{2}$

Neurologically, these patients may develop encephalopathy and signs of increased intracranial pressure 


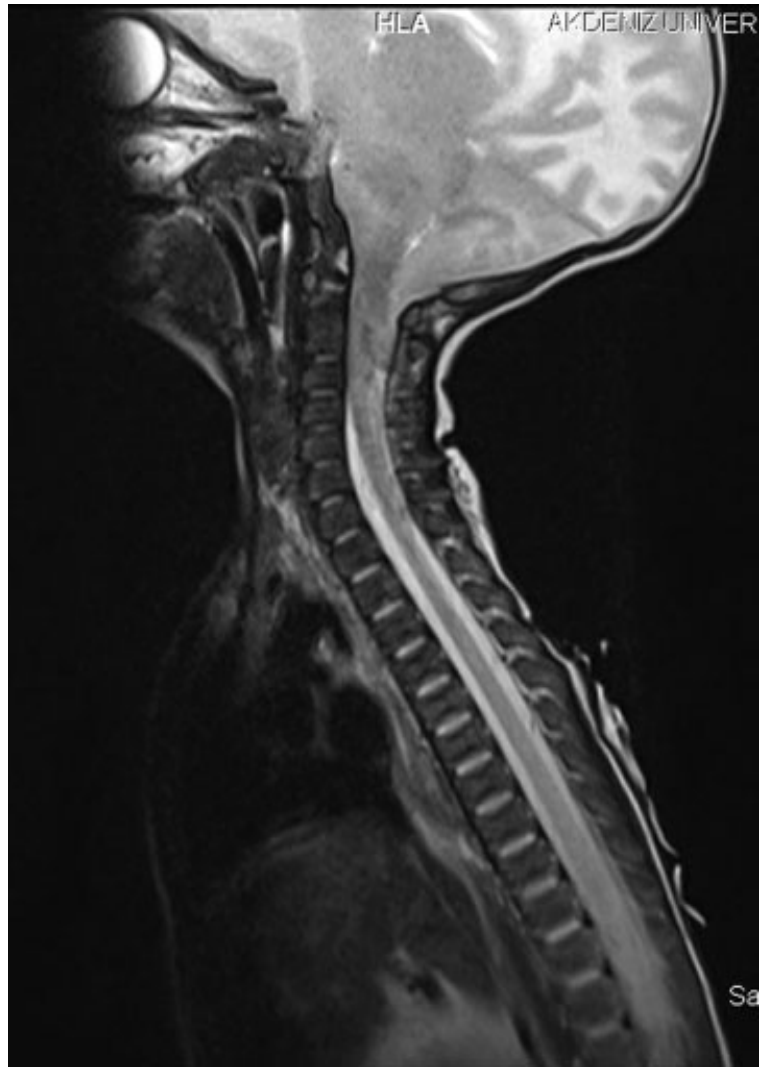

Figure 2 T2 sagittal section revealed cerebellar tonsillar herniation and compression of spinal cord.

with cerebral edema, usually after several days of more nonspecific signs. Galactosemia must be considered in the differential diagnosis of an infant with diffuse cerebral edema presenting with a bulging anterior fontanel in the setting of poor feeding, jaundice, and hepatomegaly. ${ }^{3}$

Animal models have suggested that the cerebral edema may be caused by elevations in brain galactitol concentrations and alterations in glucose, adenosine triphosphate, and phosphocreatine levels, which increase osmolality. The mechanism may be similar to that reported in a rat model with intact GALT but excessive dietary loading, in which galactitol accumulates in peripheral nerves and produces edema with increased pressure and eventual demyelination. ${ }^{4}$

Liver failure is a rare presenting feature in the neonatal period, and potential etiologies include inborn errors of metabolism, infections, ischemia, and abnormal perfusion. Common metabolic causes include galactosemia, fructosemia, tyrosinemia type 1 , and bile acid synthesis defects. ${ }^{5}$ Our infant had severe acute liver failure on presentation as evidenced by severe coagulopathy and elevated liver enzyme (international normalized ratio of 2.4). The hyperammonemia probably resulted from liver immaturity and the hepatotoxic effect of elevated galactose metabolites,
Early recognition of meningitis is of prime concern in neonates because of the increased morbidity and mortality associated with delayed or missed diagnosis. LP and a CSF examination should be performed if meningitis is suspected or if increased intracranial pressure from hydrocephalus is causing apnea and bradycardia. The most common purpose for an LP is to collect CSF in a case of suspected meningitis, because there is no other reliable tool with which meningitis, a life-threatening but highly treatable condition, can be excluded. ${ }^{6}$ LP was performed for the diagnosis of clinically suspected bacterial meningitis. Fifteen minutes after the LP, she became hypotensive with shallow respirations and exhibited decerebrate posturing. She was promptly intubated and stabilized with mechanical ventilation.

Herniation of cerebral tissue through the foramen magnum is not a common problem in neonatal intensive care units because of the open fontanelle in infants. ${ }^{7}$ Herniation in neonates is very rare, traditionally attributed to the increased compliance of the neonatal skull. In the literature, we found only two such case involving a 5day-old infant with bacterial meningitis and a 1-day-old infant with uncal herniation due to a large cerebral infarct. ${ }^{8,9}$ Possible explanations for why cerebellar herniation occurred in our patient in the absence of increased head circumference include the skull not being normally compliant, swelling and subsequent increase in intracranial pressure occurring too fast to accommodate increased volume with a normally compliant skull, or dura constraining the infarct as swelling occurred, despite a compliant skull.

Infants with galactosemia may present with signs of increased intracranial pressure, and central nervous system imaging has demonstrated the presence of diffuse cerebral edema in some cases. This will generally resolve with appropriate treatment. As in our case, fatal cerebral herniation may occur after LP. Even with an open anterior fontanelle in a newborn, LP must be done carefully.

\section{REFERENCES}

1. Bosch AM. Classical galactosaemia revisited. J Inherit Metab Dis 2006;29:516-525

2. Elsas LJ. Galactosemia. In: Pagon RA, Bird TC, Dolan CR, Stephens K, eds. GeneReviews [Internet]. Seattle, WA: University of Washington, Seattle; 1993. Available at: http:// www.ncbi.nlm.nih.gov/books/NBK1518/. Accessed February 5, 2010

3. Ridel KR, Leslie ND, Gilbert DL. An updated review of the long-term neurological effects of galactosemia. Pediatr Neurol 2005;33:153-161

4. Lai K, Elsas LJ, Wierenga KJ. Galactose toxicity in animals. IUBMB Life 2009;61:1063-1074

5. Pietrangelo A. Inherited metabolic disease of the liver. Curr Opin Gastroenterol 2009;25:209-214 
6. Riordan FA, Cant AJ. When to do a lumbar puncture. Arch Dis Child 2002;87:235-237

7. Gomella TL. Lumbar puncture. In: Gomella TL, Cunningham MD, Eyal FG, Zenk KE, eds. Neonatology: Management, Procedures, On-Call Problems, Diseases, and Drugs, 5th ed. New York: McGraw-Hill Companies; 2004:245-247
8. Thibert RL, Burns JD, Bhadelia R, Takeoka M. Reversible uncal herniation in a neonate with a large MCA infarct. Brain Dev 2009;31:763-765

9. Feske SK, Carrazana EJ, Kupsky WJ, Volpe JJ. Uncal herniation secondary to bacterial meningitis in a newborn. Pediatr Neurol 1992;8:142-144 